\title{
Comparative of infection rate in non-elective and elective surgery, and its relation on quality of life
}

\begin{abstract}
Objectives: To study infection rates in patients undergoing total hip arthroplasty, comparing elective surgery against intervention due to hip fracture (non-elective), and being related to the quality of life of them, comparing infection sample versus uninfected one.

Methods: Longitudinal prospective study of 104 patients older than 65 years who underwent hip replacement between October 2008 and March 2010, in "Consorcio Hospital General Universitario de Valencia". The EuroQol-5D was used for clinical assessment.

Results: The infection rate was $2.88 \%$ at 6 months follow-up ( 3 elective surgery infections and no one infection in hip fracture), decreasing the prevalent infection rate to $0 \%$ at 12 months. Total hip arthroplasty intervention means an increase quality of life of 0.452 in the patients studied.

Conclusion: Lower quality of life figures in patients undergoing surgery due to hip fracture $(-0.1685)$ compared to osteoarthritis $(0.5729)(\mathrm{p}<0.001)$ are obtained. Postoperative quality of life scores are similar between infected and uninfected sample (0.898 and 0.791 respectively) but health and economic impact of hip joint replacement infections are important.
\end{abstract}

Keywords: Prosthetic infection, Quality of life, Total hip arthroplasty, Hip osteoarthritis
Volume 8 Issue 6 - 2017

\author{
A Ubeda-Tomás,' A Bru-Pomer, ${ }^{2}$ J Ribes- \\ Iborra $^{3}$ \\ 'CEU-Cardenal Herrera University, Spain \\ ${ }^{2}$ Department of Orthopedic Surgery and Traumatology, \\ Consorcio Hospital General Universitario de Valencia, Spain \\ ${ }^{3}$ Department of Orthopedic Surgery and Traumatology, Hospital \\ de la Ribera, Spain
}

\begin{abstract}
Correspondence: Andrea Ubeda Tomas, Avenida Santos Patronos 32, 6, door I I, Alzira (CP. 46600) Valencia, Spain, Tel 607310666,Email a.ubedatomas@hotmail.com
\end{abstract}

Received: August II, 2017| Published: September 18, 2017

\section{Introduction}

In recent decades, surgical joint replacements have represented a significant improvement in functional capacity of patients with osteoarthritis. ${ }^{1}$ Approximately, $90 \%$ of hip joint replacements resolve the pain and functional limitation without complications over a period of 10-15 years after surgery, being therefore a more cost-effective intervention than other surgeries. However, this procedure is not exempt from risks and the complications incidence is around $4 \% .{ }^{2}$ One of the most serious and feared complication of hip joint replacement is a surgical site infection, due to the inherent emotional costs to the long process of treatment to follow, as it can cause the prosthesis failure, ${ }^{1}$ and the economic implication it has.

The infection can happen in superficial wound area, it does not mean great seriousness, it does not have a large impact on quality of life of patients and it is usually treated with antibiotics. ${ }^{3}$ This infection is produced within the first 30 days after surgery, involves only skin or incision subcutaneous tissue and meets at least one of the following criteria: pus presence at the surgical incision site, including outlet drainage site by counteropening, with or without positive culture; isolated microorganisms from fluid or incision tissue surface; at least one of the infection signs (pain or sensitivity, operated area edema, wound erythema and local warmth) and / or medical diagnosis of surgical wound superficial infection recorded in the clinical history. ${ }^{4}$ However, there is a case that shows larger problems and catastrophic consequences for the patient: an infection developed around the prosthesis (deep infection with fascias and muscles affectation), at which time, it will probably be necessary a second operation, of inspection and cleaning or, in severe cases, a permanent artificial joint removal, in addition to related antibiotic therapy. ${ }^{3}$ Deep infection criteria are: wound depth purulent drainage; wound depth spontaneous dehiscence; wound deliberately opened by surgeon / orthopaedist though culture is negative and has at least one of these signs (fever above $38^{\circ} \mathrm{C}$, localized pain or localized sensitivity, abscess or other evidence of wound depth infection) and / or medical diagnosis of surgical wound deep infection recorded in clinical history. ${ }^{4}$ Infections are mostly produced by Staphylococcus epidermidis (methicillin resistant in $30 \%$ of cases), followed by Staphylococcus aureus infections (5\% methicillin resistance). Gram negative bacilli are often observed, highlighting Escherichia coli and Pseudomonas aureoginosa..$^{5-8}$.

Tsukayama classification (used in the study) divides infection into four groups: early postoperative infection (acute onset, usually before 3-4 weeks following surgery), chronic-late postoperative infection (chronic indolent presentation after the first month after surgery), positive intraoperative cultures (microorganisms isolation and / or pus in joint replacement, without infection clinical suspicion) and acute hematogenous infection (hematogenous spread from a distant focus). ${ }^{1,5,6}$

Regarding the latest infection subgroup due to infectious source spread, there are three conditions that may facilitate the surgical site infection occurrence at long term: frequent urinary tract infections presence, recent tooth extraction (near the time of surgery) and poor dental hygiene.

Latest demographic studies report population pyramid major changes due to life expectancy increase, being elderly population the largest one. Since age is a factor that predisposes hip joint replacement, it is estimated that the number of them will increase in the coming years, being a major public health problem. Also, one of the most serious complications for patients is the nosocomial infection development after surgery, being a clinical practice priority in European countries nowadays. Hence the importance of studying this issue, assessing the quality of life of these patients who see their health deteriorates, with the final aim of trying to improve their quality of life. 


\section{Materials and methods}

Epidemiological, descriptive, prospective longitudinal study in which a questionnaire specifically designed for this study, to assess the infection presence at 6 and 12 months after surgery, is performed. In relation to the study of quality of life, it is used the Euroquol-5D health questionnaire (EQ-5D) that determines the quality of life of patients by analyzing five variables (mobility, personal care, daily activities, pain and anxiety / depression).

The study included 104 patients over 65 years who underwent total hip replacement (THR), between October 2008 and March 2010, conducted in the Consorcio Hospital General Universitario de Valencia (CHGUV), after obtaining patients informed consent.

The criteria for defining surgical infection are the Center for Disease Control and Prevention (CDC) definitions which are internationally accepted. . $^{9-11}$ "it is considered patient with infection that one who have three or more of the following signs / symptoms: fever $\left(>38^{\circ} \mathrm{C}\right)$, pain, skin induration, erythema, drainage area, blisters and, if possible, positive microbiological data".

The classifications used to categorise infections, both superficial / deep as early / late, are based on parameters and guidelines outlined in the introduction.

For statistical data processing was used SPSS programme, calculating linear regression, statistical significance, chi square, gross and adjusted relative risks, etc. The differences were analyzed and different statistical test based on the variables characteristics were applied, with a statistical significance of $\mathrm{p}=0.05$.

\section{Results}

We included in the study 104 patients undergoing total hip replacement (62.5\% women), being the income diagnoses $81.76 \%$ due to osteoarthritis (elective surgery) and $18.27 \%$ due to fractures (non elective surgery). The mean age of patients who underwent surgery for hip arthritis was 74.40 years with a standard deviation of 5.611 (minimum 65, maximum 88 years) and patients with hip fracture was 75.05 years with a standard deviation of 6.240 (minimum 67, maximum 94 years).

Quality of life of patients included in the study $(\mathrm{n}=104)$, both operated on THR by osteoarthritis and hip fracture, was 0.3281 \pm 0.37634 preoperatively and $0.7708 \pm 0.26091$ postoperatively, obtaining thus a positive increase in quality of life of $0.4520 \pm$ 0.45790 . However, if we break down the sample by both admission diagnoses studied, osteoarthritis (elective surgery) and hip fracture (non elective surgery) separately, different results are obtained.

Patients underwent THR due to hip osteoarthritis $(n=85)$ showed an increase in quality of life of $0.5729 \pm 0.36766$ (preoperative score of $0.2227 \pm 0.31839$ and postoperative $0,7941 \pm 0.25069)$. By contrast, patients underwent THR due to hip fracture $(n=19)$ showed a negative increase in quality of life, $-0.1685 \pm 0.36892$, because of the fact that preoperative quality of life values obtained $(0.7995 \pm$ $0.22442)$ were higher than those obtained in the postoperative $(0.6515$ $\pm 0.28826)$.

Statistically significant differences were observed in the increase of quality of life in terms of admission diagnosis $(p<0.001)$, obtaining the following mathematical equation: increase in quality of life $=$ $0.944-0,371 X$, where $X$ is the admission diagnosis variable $(X=1$ for osteoarthritis and $X=2$ for fracture) (Table 1) with a explained variability coefficient of $36.2 \%\left(\mathrm{R}^{2}=0.362\right)$
Table I linear regression between increase in quality of life (dependent variable) and main admission diagnosis (independent variable)

\begin{tabular}{|c|c|c|c|c|c|}
\hline \multicolumn{6}{|l|}{ Coefficients $^{\mathrm{a}, \mathrm{b}}$} \\
\hline \multirow[t]{2}{*}{ Model } & \multicolumn{2}{|c|}{$\begin{array}{l}\text { Unstandardized } \\
\text { Coefficients }\end{array}$} & \multirow{2}{*}{$\begin{array}{l}\text { Established } \\
\text { Coefficients } \\
\text { Beta }\end{array}$} & \multirow[t]{2}{*}{$\mathbf{t}$} & \multirow[t]{2}{*}{ Sig. } \\
\hline & B & Typified error & & & \\
\hline (Constant) & 944 & ,079 & & II,976 & ,000 \\
\hline $\begin{array}{l}\text { Main } \\
\text { admission } \\
\text { diagnosis }\end{array}$ &,- 371 & ,052 &,- 601 & $-7,142$ & ,000 \\
\hline
\end{tabular}

a: Hip replacement type:Total.

b: Dependent variable: Increase in quality of life.

It appeared a total of 3 infections during the first 6 months followup of the study ( $\mathrm{n}=104)$, representing $2.88 \%$ of infections (infection rate). These three infections occurred in patients who received elective surgery due to osteoarthritis. Therefore, the infection rate was 3.5\% in this group, with no statistically significant differences between men and women $(p=0.140)$ and by age of patients $(p=0.519)$. The fact that all infections were produced in elective surgery population and no one in hip fracture sample is apparently due to the difference related to the number of members in both groups ( 85 and 19 respectively), therefore finding infections in larger samples is statistically more likely.

The three infections reported were superficial, there being no deep or mixed infections (superficial infection that becomes deep). No infection was recorded in patients admitted for hip fracture. In the group of patients undergoing THR due to osteoarthritis, bloody exudate and drainage were the signs / symptoms more common observed, on the other hand, itching and induration were relatively rare in the sample studied. However, in the group of patients undergoing THR due to hip fracture, the only signs / symptoms recorded were fever and bloody exudate, not showing any of the other ones (Figure 1).

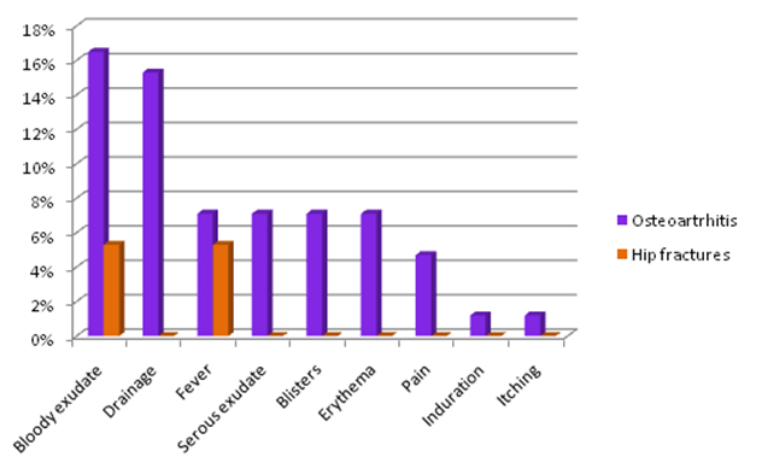

Figure I Infection signs and symptoms (6 months post-discharge).

In hip osteoarthritis sample, no statistically significant differences were observed in signs/symptoms distribution between men and women, except for blisters $(p=0.036)$ and serous exudate $(p=0.036)$ which was preferably done in women. No significant differences in signs/symptoms depending on patients age were observed, except for pain $(p=0.035)$ being assessed in older patients. In patients admitted for hip fracture, no sign/symptom presented differences according to gender $(\mathrm{p}>0.5)$ or age $(\mathrm{p}>0.5)$.

It was observed that there was no significant correlation between infection development and length of hospital stay $(\mathrm{p}=0.680)$, nor with intervention duration variable $(p=0.929)$ (results adjusted by gender and age). 
In reference to three conditions that may facilitate the infection onset in the operated area by an infection spread, $9.4 \%$ of patients receiving elective surgery claimed to have recurrent urinary tract infections, with no statistically significant differences between men and women $(p=0.568)$ and age $(p=0.173) .2 .4 \%$ of patients responded have made dental extraction a few weeks before surgery, with no difference between men and women $(p=0.657)$ and age $(p=0.099)$. And none of the respondents said poor dental cleaning performed. Then, studying the association between the first two variables mentioned above and the onset of an infection after surgery, no cause-effect statistically significant $(\mathrm{p}=0.741$ and $\mathrm{p}=0.930$ respectively) was observed.

All the infections were manifested as an early type, no statistically significant differences by gender $(p=0.198)$ and age of patients $(p=$ 0.278 ) were found.

The hospital stay (measured in days) varied between osteoarthritis patients who suffered infections after surgery (7.33 with a SD 5.77) and those who did not suffer infection (7.28 with a SD 1.336), with no statistical differences $(p=0.946)$. On the other hand, the hospital stay of patients with hip fracture was 11.36 with a SD 3,436, being greater than osteoarthritis sample. In fractured population could not be possible to compare infection variable because it did not show any infection during the study.

Infected patients quality of life was compared to uninfected population in osteoarthritis sample (Table 2), which cannot be done do with fractured patients by the absence of infection. Similar values were observed in both groups, infected and uninfected, both preoperatively and postoperatively. Even a slightly higher increase in quality of life in patients who developed infection before 6 months after surgery. However, no statistically significant differences when comparing the increases in quality of life in both groups $(p=0.879)$ were found.

Table 2 quality of life of infected and uninfected patients

\begin{tabular}{llll}
\hline Osteoarthritis & $\begin{array}{l}\text { EQ-5D } \\
\text { Preoperative }\end{array}$ & $\begin{array}{l}\text { EQ-5D } \\
\text { Postoperative }\end{array}$ & $\begin{array}{l}\text { Increase in } \\
\text { Quality of Life }\end{array}$ \\
\hline Infection & $0.2087 \pm 0.32956$ & $0.8980 \pm 0.14425$ & $0.6125 \pm 0.28214$ \\
No infection & $0.2233 \pm 0.32005$ & $0.7913 \pm 0.25291$ & $0.5719 \pm 0.37109$
\end{tabular}

It was reassessed the presence of infection after a year follow-up (from the sixth month until the year), being reduced to 0 infections in this case. Signs and symptoms reflected an improvement one year after the procedure (Figure 2) compared with those collected 6 months after discharge, except for pain variable which increased in both osteoarthritis (21.2\% of patients) and fractured sample (15.8\%). The other variables decreased. Only pain variable showed significant differences between men and women $(p=0.015)$ in osteoarthritis patients, presenting more pain women than men. By contrast, all other variables behaved similarly, without statistically significant differences between men and women or age of the patients in both admission diagnosis groups ( $\mathrm{p}>0.05)$.

It is unable to study quality of life of patients who developed infection after sixth month after surgery for lack of sample, since no infection was recorded in this period of the study. The three infections recorded until six months after surgery, studied previously, reversed and cured, thus finding no infections from the sixth month until the year of study.

\section{Discussion}

Hip replacement is one of the most popular and successful reconstructive procedures in orthopaedic surgery in recent years. At the moment, it represents $35 \%$ of all orthopaedic procedures. ${ }^{12}$ It mainly affects females and elderly patients, who demonstrate a high proportion of osteoarthritis (OA) and hip fractures.

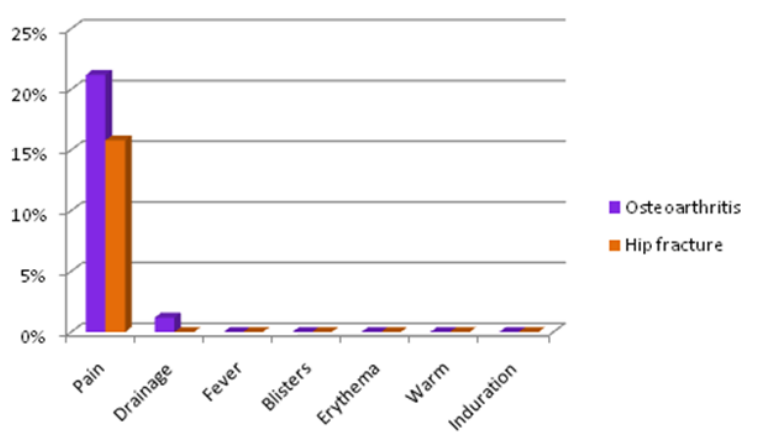

Figure 2 Infection signs and symptoms (from 6 months post-discharge to the year follow-up).

The mean age of patients undergoing total hip replacement due to hip osteoarthritis was 74 year and due to hip fracture was 75 years, which is consistent with other studies of quality of life in patients with osteoarthritis $(\mathrm{OA})$, where the population is over 60 years. ${ }^{13-16}$ However, the mean age of patients is slightly higher in our study because of the fact that the sample was limited to patients older than 64 years (inclusion criterion), so the mean age is higher compared to the published literature.

A noticeable predominance of females in the sample $(62.5 \%)$ was observed, which is consistent with other published studies that indicate an increased female involvement frequency ${ }^{14,16-18}$ Quality of life studies conducted in England, Scotland, Switzerland, New Zealand, Sweden, the Netherlands, Japan, etc. related to hip joint replacements also highlight the highest percentage of women in the sample: $58 \%,{ }^{19} 62 \%,{ }^{20} 64 \%,{ }^{21}$ etc.

It appeared 3 infections during the first 6 months follow-up study (out of 104 patients undergoing total hip replacement in the Orthopaedic Surgery Service), representing an infection rate of $2.88 \%$. This infection prevalence figure is similar to those reported by other studies and what the EPINE considered "within normal limits". Currently, hip arthroplasty infection rate are around $1.5 \%,{ }^{22-27}$ being published rates range between $0.86 \%$ and $4.8 \%$. In a study conducted in a secondary level hospital of Lleida (Hospital Universitario de Arnau de Vilanova) between 1994 and 2003, the hip replacement infection rate was $1.2 \%{ }^{8}$ However, higher infection rates were reported in another study carried out by Galvan, F. et al. (2006) in Bogotá, reaching 3.2\%. ${ }^{28}$

Nevertheless, since the registered infections all belong to the group of patients undergoing surgery due to hip osteoarthritis, infection rate in this sample $(\mathrm{n}=85)$ is $3.5 \%$. This result is slightly higher (but within the normal range) than other related studies ${ }^{8-22-29}$ and as recommended by the Spanish Society of Infectious Diseases and Clinical Microbiology. ${ }^{26}$ The explanation for this infection rate could be that, according to CDC criteria, in our study one infection was considered by the concurrence of three or more signs (heat, blush, pain, irritation at site, fever, etc.), while other studies rated one infection if it had positive microbiological tests. The three infections collected during the study were superficial, presenting few problems when compared to studies that show deep infections, needing second interventions of cleaning, checking or prosthesis removal. Apart from that, the fact that no infection was appeared in hip fracture group is related to the sample size, being in this group much smaller (19 patients) in comparison with elective surgery population ( 85 patients). 
It is reassessed the presence of infection after the monitoring year (12 months follow-up), being in this case the infection rate $0 \%$, as all three infections registered reverse and cure. By studying the signs / symptoms one year after the intervention, an improvement is observed in comparison to those collected at 6 months after discharge.

According to published studies, the quality of life of patients with hip osteoarthritis improved after the implantation of a prosthesis, reducing pain and improving joint mobility. Preoperative quality of life scores of $0.32,{ }^{30} 0.35^{20}$ and $0.36^{31}$ increase to postoperative scores of $0.72,,^{30} 0.76^{20}$ and $0.77^{31}$ respectively after the procedure. These figures are similar to this study one, with a quality of life preoperative score of patients undergoing hip replacement due to osteoarthritis of 0.222 and a postoperative score of 0.794 . The explanation for this preoperative score lower than published literature could be the sample age, oldest patients in this case.

However, patients undergoing THR due to a hip fracture show preoperative and postoperative quality of life scores more similar to each other (0.799 and 0.652 respectively), obtaining an increase in quality of life lower than the other studied group with osteoarthritis patients. The possible explanation is that preoperative score refers to patient quality of life one week before admission (information collected by personal interview during patient admission), at which point patients had not probably suffered the hip fracture yet, so their answers from EQ-5D survey are more satisfying than the other admission diagnosis contemplated (osteoarthritis). After suffering the fracture they are operated emergency and procedure is intended to restore at least the same quality of life they had before, which is not always achieved.

It is hoped that the quality of life decreases in patients who develop a prosthetic infection, postoperative quality of life scores are lower when compared to operated sample which do not develop infection, due to problems associated with infection. Nevertheless, there are no published data about patients undergoing hip replacement who develop infection, not being possible to compare with patients without infection. Hence the interest of this study linking hip replacement infection rates with patient's quality of life.

Studies relating to quality of life in patients undergoing hip arthroplasty, are increasingly used and useful, not only at European level (the UK, Switzerland, Netherlands, etc.), but worldwide (Canada, Australia, Japan, etc.), then expect to know the features of them and make appropriate improvements in areas of health care and health economics (allocation of health resources). In assessing the outcome of treatment, employing patient reported outcome measures questionnaires is now considered an indispensable part, ${ }^{32-34}$ as it has been argued that patient-based outcome measures provide a feasible and valid measure of health status that complements existing approaches, especially in so far as they focus upon felt and experienced health problems. ${ }^{35}$

\section{Conclusion}

A. The infection rate in all patients was $2.88 \%$ six months after surgery which decreased to $0 \%$ between 6 months and a year after surgery.

B. All infections occurred in patients undergoing total hip replacement due to osteoarthritis (elective surgery), manifesting all of them as premature and superficial.

C. No infection appeared in hip fracture group, apparently due to the shortage of sample in this group of patients.
D. Total hip replacement procedure means an increase in quality of life of 0.452 in the studied sample $(\mathrm{n}=104)$.

E. Sample breakdown by two income diagnoses selected shows that osteoarthritis patients quality of life after procedure is higher (postoperative score 0.794) compared to patients admitted for hip fracture (postoperative score 0.652).

F. Postoperative quality of life of patients who develop infection is very similar to that obtained for the group of patients without infection ( 0.898 and 0.791 respectively), no significant difference was observed $(\mathrm{p}=0.879)$.

G. Decrease in postoperative deep infection prevalence has been accompanied by a steady increase in the frequency with which this operation is performed, so it is advisable to try to minimize the complications resulting from it, especially infections surgical site.

\section{Acknowledgments}

None.

\section{Conflicts of interest}

None.

\section{References}

1. Rodríguez C, Zazo M, García M, et al. Early complications of primary total hip arthroplasty. Revista Española De Cirugía Osteoarticular. 2005;40(221):13-17.

2. Sarasqueta C, Escobar A, Arrieta Y, et al. Primary hip replacement: First year results and predictive factors of poor outcome. Revista Española De Cirugía Ortopédica y Traumatología. 2012;56(1):3-10.

3. Merollini KM, Crawford R. W, Whitehouse S L, et al. Surgical site infection prevention following total hip arthroplasty in Australia: A cost-effectiveness analysis. American Journal of Infection Control. 2013;41(9):803-809.

4. Alcoholada I. Prevención de infecciones del sitio quirúrgico. Hospital de niños Roberto del Río (Chile). Recuperado. 2014.

5. Lara J, Irribarra L, Mardones R. Diagnóstico y manejo de la artroplastia de cadera infectada. Rev Chil Infec. 2000;17(12):92-100.

6. Masterson EL, Masri BA, Duncan CP. Treatment of infection at the site of total hip replacement. J Bone Joint Surg Am. 1997;79(A):1740-1749.

7. Gómez J, Herrero F, Ruiz J. Profilaxis antibiótica en cirugía: Situación actual y uso razonado. Revista Española De Quimioterapia. 1997; 10:36-42.

8. Jover A, Barcenilla F, Torres J, et al. Infección de prótesis total de rodilla y cadera: Epidemiología descriptiva terapéutica y evolución en un hospital de segundo nivel durante 10 años. Anales De Medicina Interna. 2007;24(1):19-23

9. Mangram AJ, Horan TC, Pearson ML, et al. Guideline for prevention of surgical site infection 1999. Centers for Disease Control and Prevention Hospital Infection Control Practices Advisory Committee. Am J Infec Cont. 1999;27(2):97-132.

10. Mangram AJ, Horan TC, Pearson ML, et al. Guideline for prevention of surgical site infection 1999. Hospital Infection Control Practices Advisory Committee. Infection Control and Hospital Epidemiology: The Official Journal of the Society of Hospital Epidemiologists of America. 1999;20(4):250-278.

11. Garner JS, Jarvis WR, Emori TG, et al. CDC definitions for nosocomial infections 1988. American J Infect Cont. 1988;16(3):128-140. 
12. Fracturas de la extremidad proximal y de la diáfisis del fémur. Recuperado. 2012

13. Góngora Y, Friol J, Rodríguez E, et al. Calidad de vida en pacientes con osteoartrosis de cadera y rodilla. Rev Cubana De Reumatología VIII. 2006:9-10.

14. Dieppe P, Judge A, Williams S, et al. Variations in the pre-operative status of patients coming to primary hip replacement for osteoarthritis in European orthopaedic centres. BMC Musculoskelet Dis. 2009;10:19.

15. Michel JP, Klopfenstein C, Hoffmeyer P, et al. Hip fracture surgery: Is the pre-operative American Society of Anesthesiologists (ASA) score a predictor of functional outcome? Aging Clinical and Experimental Research. 2002;14(5):389.

16. Kirkness CS, McAdam-Marx C, Unni S, et al. Characterization of patients undergoing total hip arthroplasty in a real-world setting and pain-related medication prescriptions for management of postoperative pain. J Pain Palliat Care Pharmacother. 2012;27(3):235-243.

17. Rao S, Cherukuri M. Management of hip fracture: The family physician's role. American Family Physician. 2006;73(12):2195-2200.

18. Dougados M, Gueguen A, Nguyen M, et al. Requirement for total hip arthroplasty: An outcome measure of hip osteoarthritis? J Rheumatolo. 1999;26(4):855-861.

19. Rolfson O. Patient-reported outcome measures and health.economic aspects of total hip arthroplasty. Institute of Clinical Sciences Sahlgrenska Academy University of Gothenburg (Sweden). 2010.

20. Ostendorf M, van Stel HF, Buskens E, et al. Patient-reported outcome in total hip replacement. A comparison of five instruments of health status. J Bone Joint Surg. 2004;86(6):801-808

21. Uesugi Y, Makimoto K, Fujita K, et al. Validity and responsiveness of the oxford hip score in a prospective study with Japanese total hip arthroplasty patients. Journal of Orthopaedic Science. 2009;14(1):35-39.

22. Gómez J, Rodríguez M, Banos V, et al. Infections in joint prostheses: Epidemiology and clinical presentation. A prospective study 1992-1999 [Infección de prótesis articulares: epidemiología y clínica. Estudio prospectivo 1992-1999]. Enfermedades Infecciosas y Microbiología Clínica. 2002;20(2):74-77.

23. García J, Blanch J, Coll R, et al. Infección de prótesis articulares: Estudio prospectivo en 5 hospitales de Cataluña. Enfermedades Infecciosas y Microbiología Clínica. 2006;24(3):157-161.

24. Otaiza F, Brenner P. Infecciones en cirugía de artroplastia de cadera: Resultados del sistema de vigilancias epidemiológica de las infecciones intrahospitalarias. 1996-1999. Revista Chilena De Infectología. 2000;17(2):101-108
25. Gómez J, Banos V, Simarro E, et al. Nosocomial fungemias in a general hospital. epidemiology and prognostic factors. Prospective study 1993-1998. [Fungemias nosocomiales en un hospital general: epidemiología y factores pronostico. Estudio prospectivo 1993-1998] Enfermedades Infecciosas y Microbiología Clínica. 2001;19(7):304-307.

26. Documento técnico de vigilancia y control de la infección nosocomial. Grupo de Estudio de Infección Hospitalaria de la Sociedad Española de Enfermedades Infecciosas y Microbiología Clínica.

27. Plowman R, Graves N, Griffin MA, et al. The rate and cost of hospitalacquired infections occurring in patients admitted to selected specialties of a district general hospital in England and the national burden imposed. The J Hosp Infect. 2001;47(3):198-209.

28. Galván F, Bernal FA, Páez JM, et al. Evolución clínica y radiológica de pacientes intervenidos de artroplastia total de cadera con prótesis de resuperficialización metal-metal. Reporte preliminar. Revista Colombiana De Ortopedia y Traumatología. 2006;20(4):45-57.

29. Salavert M, Martinez J, Sanchez C, et al. Hip prosthesis infection: Diagnostic approach and treatment of 27 cases. Enfermedades Infecciosas y Microbiología Clínica. 1994;12(10):490-496.

30. Jenkins P J, Clement ND, Hamilton DF, et al. Predicting the costeffectiveness of total hip and knee replacement. A health economic analysis. Bone Joint J. 2013;95-B(1):115-121.

31. Hutchings A, Grosse Frie K, Neuburger J, et al. Late response to patientreported outcome questionnaires after surgery was associated with worse outcome. Journal of Clinical Epidemiology. 2013;66(2):218-225.

32. Impellizzeri FM, Mannion AF, Naal FD, et al. A core outcome measures index (COMI) for patients undergoing hip arthroplasty. The Journal of Arthroplasty. 2013;28(9):1681-1686.

33. Bream E, Nick B. What is the relationship between patients' and clinicians' reports of the outcomes of elective surgery? Journal of Health Services Research \& Policy. 2009;14(3):174-182.

34. Frost MH, Reeve BB, Liepa AM, et al. What is sufficient evidence for the reliability and validity of patient-reported outcome measures? Value in Health: The Journal of the International Society for Pharmacoeconomics and Outcomes Research. 2007;10(2):94-105.

35. What are patient-based outcome measure? Health Technology Assessment. 1998;2(14):3-18. 